\title{
Effects of cardiopulmonary bypass with low-priming volume on clinical outcomes in children undergoing congenital heart disease surgery
}

Lei Wang ${ }^{*}$, Qiang Chen, Yong Qiang Qiu, Jian Xi Ye, Jian Zhi Du, Xiao Chai Lv, Yan Ting Hou and Liang Wan Chen ${ }^{*}$

\begin{abstract}
Background: Cardiopulmonary bypass (CPB) with high-priming volume can significantly activate the inflammatory response and increse the usage of packed red blood cells (PRBCs). As risks and complications related to transfusions are increasing, many cardiac centers are focusing on reducing the priming volume of CPB. In our center, efforts have also been made to reduce the priming volume, and the effects of CPB with low-priming volume on clinical outcomes in children undergoing congenital heart disease (CHD) surgery were investigated in this study to provide referential experiences for pediatric CPB.

Methods: The clinical case data of 158 children undergoing CHD surgery with CPB were collected. The children were divided into the low-priming-volume group (group $A, n=79$ ) and the traditional group (group $B, n=79$ ) according to the priming volume. The amount of PRBCs transfused, the postoperative hematological test results and the clinical outcomes of the two groups were compared by the independent sample $t$-test or the chi-square test.

Results: The amount of PRBCs transfused during CPB and during the whole operation were significantly lower in group A than in group $B(p<0.01)$, but the hemoglobin $(\mathrm{Hb})$ concentration was higher in group A on the first day after surgery $(p<0.01)$ and before hospital discharge. However, the latter showed no statistical significant difference. The lowest postoperative platelet count was higher in group A than in group B $(p<0.05)$. There was no statistical difference in the postoperative inflammatory markers and the main clinical outcomes between the two groups.

Conclusions: The usage of PRBCS in CPB with low-priming volume decreased significantly, but the postoperative $\mathrm{Hb}$ concentration and platelet count could still be maintained at a high level, improving the use efficiency of PRBCs. CPB with low-priming volume did not affect the postoperative recovery of patients, so it is worthy of continuous promotion and optimization.
\end{abstract}

Keywords: Cardiopulmonary bypass, Low-priming volume, Children, Congenital heart disease surgery

*Correspondence: 18860117005@163.com; clw1259@163.com Department of Cardiac Surgery, Union Hospital of Fujian Medical University, Fuzhou, Fujian Province, China

(c) The Author(s). 2020 Open Access This article is licensed under a Creative Commons Attribution 4.0 International License, which permits use, sharing, adaptation, distribution and reproduction in any medium or format, as long as you give appropriate credit to the original author(s) and the source, provide a link to the Creative Commons licence, and indicate if changes were made. The images or other third party material in this article are included in the article's Creative Commons licence, unless indicated otherwise in a credit line to the material. If material is not included in the article's Creative Commons licence and your intended use is not permitted by statutory regulation or exceeds the permitted use, you will need to obtain permission directly from the copyright holder. To view a copy of this licence, visit http://creativecommons.org/licenses/by/4.0/ The Creative Commons Public Domain Dedication waiver (http://creativecommons.org/publicdomain/zero/1.0/) applies to the data made available in this article, unless otherwise stated in a credit line to the data. 


\section{Introduction}

Congenital heart disease (CHD) surgery in children accounts for a large part of cardiac surgery. The pathophysiological changes during cardiopulmonary bypass $(\mathrm{CPB})$ in children are quite different from those in adults [1]. Children have a small body weight and blood volume, so the priming volume of $\mathrm{CPB}$ is a relatively large volume compared with adults. This means that the contact between the blood and the non-endothelial biomaterial surface increases, which activates the inflammatory response and coagulation system significantly substantially. Animals studies shows that when the priming volume been decreased by $50 \%$, the levels of the inflammatory markers of TNF- $\alpha$ and IL- 6 are lowered during $\mathrm{CPB}$ at $60 \mathrm{~min}$ [2]. On the other hand, the increased priming volume results in significant hemodilution and leads to increase the usage of PRBCs. However, the risks and complications related to transfusions are increasing [3-6]. Transfusions are even associated with increased mortality, becoming an independent risk factor of postoperative mortality [4]. Therefore, it is particularly important to reduce the priming volume of $\mathrm{CPB}$, and at present more and more cardiac centers are focusing on it to alleviate the series of non-physiological reactions described above and reduce the use of blood products [7, 8]. But as a matter of fact there are no uniform guidelines and standards for pediatric $\mathrm{CPB}$ nowadays, different cardiac centers or even different perfusionists in the same center have different experiences [9]. Miniaturizing CPB tubes is the most important way to decrease the priming volume, but whether the CPB with low-priming volume is always better is uncertain. In our center, since 2016, we have reduced the priming volume of $\mathrm{CPB}$ by reducing the lengths and the inner diameters of the CPB tubes, and since 2019 a membrane oxygenator integrated with a microembolus filter has been used to further reduce the priming volume. We want to analyze the results of our work and guide future work further as well as provide referential experiences for pediatric $\mathrm{CPB}$. So this study retrospectively analyzed the effects of $\mathrm{CPB}$ with low-priming volume on clinical outcomes in children undergoing CHD surgery.

\section{Methods}

\section{Grouping}

The clinical case data of 158 children undergoing CHD surgery with CPB in our hospital from May 2017 to August 2019 were collected. According to the priming volume of $\mathrm{CPB}$, the patients were divided into the lowpriming-volume group (group $\mathrm{A}, n=79$ ) and the traditional group (group A, $n=79$ ).

Diagnostic criteria, inclusion criteria and exclusion criteria Diagnostic criteria: All patients were clearly diagnosed according to clinical manifestations, echocardiography and chest radiographs. Inclusion criteria: Patients with a body weight $\leq 15 \mathrm{~kg}$ and the priming volume of $\mathrm{CPB}$ was 110 to $350 \mathrm{ml}$; patients who had undergone selective uncomplicated CHD surgery with $\mathrm{CPB}$ and the risk adjustment in congenital heart surgery (RACHS-1) category was 1 to 2; the hemodynamics before surgery was stable. Exclusion criteria: Transfusion of PRBCs was required because of severe anemia preoperatively; secondary thoracotomy or endotracheal intubation was performed postoperatively; early clinical death occurred within $48 \mathrm{~h}$ after surgery.

\section{Main clinical outcomes}

The main clinical outcomes included the usage rate and amount of PRBCs perioperatively, the changes of hemoglobin $(\mathrm{Hb})$ concentration, platelet count and inflammatory markers including the maximum values of white blood cell (WBC) number, eutrophils percentage, Creactive protein (CRP), blood glucose, body temperature, the incidence of pneumonia, the urine volume and thoracic drainage fluid $48 \mathrm{~h}$ after surgery, the postoperative mechanical ventilation time, the length of ICU stay and the postoperative stay in the general ward.

\section{The priming of $\mathrm{CPB}$}

A Stockert type III or V CPB machine was used. The priming volumes of $\mathrm{CPB}$, the lengths and the inner diameters of the CPB tubes of the two groups are shown in Table 1 . The lowest priming volume of CPB was 110 $\mathrm{ml}$, as shown in Fig. 1. In group A, the priming volume was $110 \sim 180 \mathrm{ml}$. The membrane oxygenator used included two types, the Terumo RX05 and the Terumo FX05. The latter oxygenator was integrated with a microembolus filter not requiring an additional one, so it reduced the priming volume by about $65 \mathrm{ml}$. The inner diameters of the $\mathrm{CPB}$ tubes used in children with body weights $\leq 10 \mathrm{~kg}$ were gradient, that is, the diameters of the venous tube and the tube in the main pump were $1 / 4$ in., and the diameters of the rest tubes were $3 / 16$ in. On the other hand, the oxygenator was located close to the main pump and the operating bed with the shortened tubes. Under this circumstances, the oxygenator was almost at the same height as the operating bed, reducing the venous drainage assisted by gravity. So a vacuum-assist venous drainage (VAVD) controller was needed to facilitate venous drainage with a negative pressure from $-20 \mathrm{mmHg}$ to $-40 \mathrm{mmHg}$. In group $\mathrm{B}$, like group $\mathrm{A}$, two types of oxygenators was used, but the lengths of the $\mathrm{CPB}$ tubes were longer, and the inner diameters of the $\mathrm{CPB}$ tubes were all $1 / 4 \mathrm{in}$. regardless of the weights of children. So the priming volume in group B with a volume of $210 \sim 350 \mathrm{ml}$ was more than that in group $\mathrm{A}$, and the oxygenator was located at a certain height and distance from the operating bed, with venous 
Table 1 The priming volume of CPB, the lengths and the inner diameters of the CPB tubes

\begin{tabular}{|c|c|c|c|c|c|c|c|c|}
\hline Group & $\begin{array}{l}\text { Body } \\
\text { weight }\end{array}$ & $\begin{array}{l}\text { Membrane } \\
\text { oxygenator }\end{array}$ & $\begin{array}{l}\text { Priming } \\
\text { volume }(\mathrm{ml})\end{array}$ & $\begin{array}{l}\text { Length of CPB } \\
\text { tubes }(\mathrm{cm})\end{array}$ & $\begin{array}{l}\text { Diameter of arterial } \\
\text { tube (inches) }\end{array}$ & $\begin{array}{l}\text { Diameter of venous } \\
\text { tube (inches) }\end{array}$ & $\begin{array}{l}\text { Diameter of main } \\
\text { pump tube (inches) }\end{array}$ & $\begin{array}{l}\text { Diameter of the rest } \\
\text { CPB tubes (inches) }\end{array}$ \\
\hline \multirow[t]{4}{*}{ group A } & $\leq 10 \mathrm{~kg}$ & FX05 & $110-120$ & 255 & $3 / 16$ & $1 / 4$ & $1 / 4$ & $3 / 16$ \\
\hline & & RX05 & 150-160 & 320 & $3 / 16$ & $1 / 4$ & $1 / 4$ & $3 / 16$ \\
\hline & $10-15$ kg & FX05 & $130-140$ & 255 & $1 / 4$ & $1 / 4$ & $1 / 4$ & $1 / 4$ \\
\hline & & RX05 & $170-180$ & 320 & $1 / 4$ & $1 / 4$ & $1 / 4$ & $1 / 4$ \\
\hline \multirow[t]{2}{*}{ group B } & $\leq 15 \mathrm{~kg}$ & FX05 & 210-300 & 395 & $1 / 4$ & $1 / 4$ & $1 / 4$ & $1 / 4$ \\
\hline & & RX05 & $250-350$ & 460 & $1 / 4$ & $1 / 4$ & $1 / 4$ & $1 / 4$ \\
\hline
\end{tabular}

$C P B$ cardiopulmonary bypass

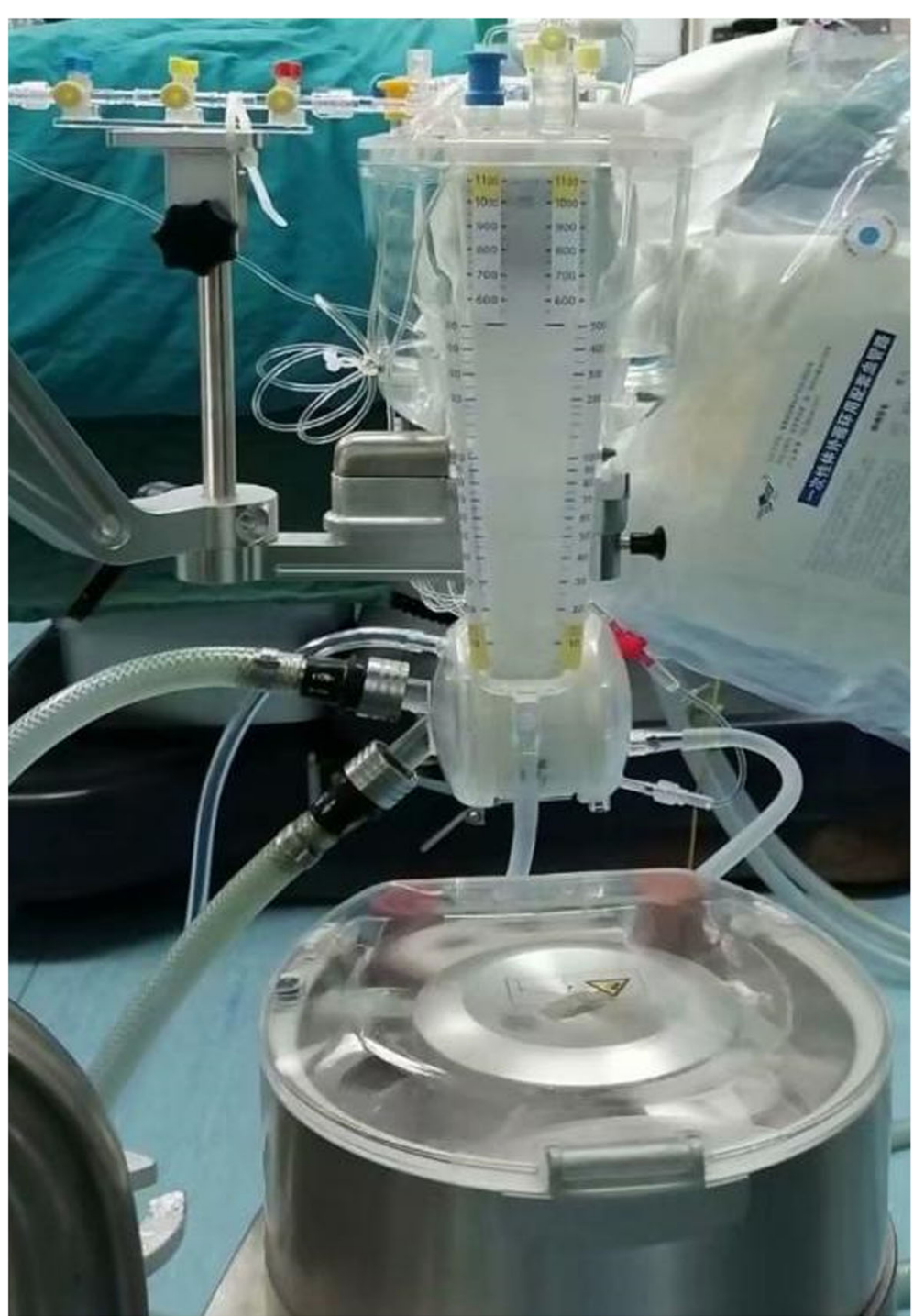

Fig. 1 The CPB with low-priming volume. The lowest priming volume was $110 \mathrm{ml}$ in our study by using a microembolus-filter integrated oxygenator and shorter and thinner tubes. The oxygenator was located close to the pump and the operating bed 
drainage assisted by gravity effectively. In the both groups, the priming liquid used was compound sodium chloride, and an appropriate amount of PRBCs was used in the priming of $\mathrm{CPB}$ according to the patient's body weight and preoperative $\mathrm{Hb}$ concentration. Some of the patients whose body weights $\geq 8 \mathrm{~kg}$ and whose preoperative $\mathrm{Hb}$ concentrations $\geq 11 \mathrm{~g} / \mathrm{dL}$ were treated with bloodless priming, using Voluven or $20 \%$ albumin to replace the most initial priming liquid. A moderate amount of plasma was transfused during $\mathrm{CPB}$ in group B.

\section{Management during CPB}

All patients underwent general anesthesia with endotracheal intubation. A shallow low temperature and high flow perfusion was adopted during CPB. The cardioplegic solution was histidine-tryptophan-ketoglutarate solution with a dose of $40 \sim 60 \mathrm{ml} / \mathrm{kg}$. The conventional ultrafiltration was performed to remove excess fluid and to increase the $\mathrm{Hb}$ concentrations. The lowest acceptable $\mathrm{Hb}$ concentration during $\mathrm{CPB}$ was $7 \mathrm{~g} / \mathrm{dL}$, and before $\mathrm{CPB}$ weaning the $\mathrm{Hb}$ concentration should be greater than $9 \mathrm{~g} / \mathrm{dL}$. In group $\mathrm{A}$, not all PRBCs prepared in advance were transfused during $\mathrm{CPB}$. When the $\mathrm{Hb}$ concentration reached the standard of $\mathrm{CPB}$ weaning, the remaining $\mathrm{PRBCs}$ were transfused through a peripheral vein by the anesthesiologist after $\mathrm{CPB}$ weaning. Unlike this, in group B, almost all PRBCs prepared were transfused during $\mathrm{CPB}$. The mean arterial pressure, central venous pressure, mixed venous oxygen saturation $\left(\mathrm{SvO}_{2}\right)$, negative pressure in the reservoir, blood gas analysis, activity coagulation time and nasopharyngeal temperature were continuously monitored during $\mathrm{CPB}$, and all parameters were adjusted within the normal range.

\section{Statistical methods}

Statistical analysis was performed with SPSS version 25 . Descriptive analysis was carried out for each variable. The measurement data were expressed as $(\bar{x} \pm S)$, and an independent sample $t$-test was used to compare the measurement data between the two groups. The enumeration data were expressed as the frequency or rate, and the chi-square test was used to compare the enumeration data between the two groups. Values of $p<0.05$ were considered to be statistically significant.

\section{Results}

Comparison of the preoperative clinical data between the two groups

As shown in Table 2, there were no significant differences between the two groups in terms of the preoperative data.

\section{Comparison of the intraoperative clinical data between the two groups}

As shown in Table 3, the priming volume of $\mathrm{CPB}$ and the PRBCs used in the priming of $\mathrm{CPB}$ were significantly lower in group A than in group $\mathrm{B}(p=0.000)$. The total amount of PRBCs transfused during $\mathrm{CPB}$ and during the whole operation was significantly lower in group $A$ than in group $\mathrm{B}(p<0.01)$. The $\mathrm{Hb}$ concentration during $\mathrm{CPB}$ and before $\mathrm{CPB}$ weaning was lower in group $\mathrm{A}$ than in group B $(p<0.01)$.

\section{Comparison of the postoperative clinical data between the two groups}

As shown in Table 4, the $\mathrm{Hb}$ concentration was higher in group A than in group B on the first day after surgery $(p=0.000)$ and before hospital discharge (the latter had no statistically significance). The lowest postoperative platelet count was higher in group A than in group B $(p<0.05)$, but none of the two groups met the standard of platelet transfusion. There were no statistically significant differences between the two groups in terms of the inflammatory markers, the incidence of pneumonia, the value of total bilirubin or creatinine, the volume of urine or thoracic drainage fluid $48 \mathrm{~h}$ after surgery. And there were also no statistically significant differences between the two groups in terms of the mechanical ventilation time, the lengths of ICU stay or the postoperative stay in the general ward. There were no positive blood culture, serious liver or kidney dysfunction, neurological complications or deaths in either group postoperatively.

\section{Discussion}

In our study, the cases were all children undergoing simple CHD surgery, and children undergoing complicated CHD surgery or in a critical condition were excluded as their severe illness may be accompanied by other disturbances and may result in a lower transfusion threshold.

$\mathrm{CPB}$ equipment determines the priming volume. Improving $\mathrm{CPB}$ equipment is the most fundamental measure to reduce the priming volume, and miniaturizing $\mathrm{CPB}$ tubes is the most important one. In this study, the lowest priming volume of $\mathrm{CPB}$ was $110 \mathrm{ml}$ by reducing the lengths and the inner diameters of the $\mathrm{CPB}$ tubes and by using the oxygenator integrated with a microembolus filter. These measures significantly reduced the priming volume, but the following situations also need to be noted. Firstly, the distance and height of the oxygenator were located close to the operation bed weakening the venous drainage via gravity and leading to edema of brain and abdominal viscera probablely. So the VAVD controller played an important role as it promotes the venous drainage. When a VAVD controller is used, a thinner venous tube can be used, which is beneficial for reducing the priming volume of $\mathrm{CPB}[10]$. During $\mathrm{CPB}$ 
Table 2 Comparison of the preoperative clinical data between the two groups

\begin{tabular}{|c|c|c|c|}
\hline Preoperative data & Low-priming-volume group (group A, $n=79$ ) & Traditional group (group $B, n=79$ ) & $p$ value \\
\hline male/case & 48 & 48 & \\
\hline age/month (range) & $1 \sim 48(13.66 \pm 12.59)$ & $1.5 \sim 48(14.51 \pm 13.31)$ & 0.681 \\
\hline body weight/kg (range) & $4 \sim 15(8.62 \pm 3.31)$ & $4 \sim 15(8.91 \pm 3.35)$ & 0.859 \\
\hline \multicolumn{4}{|l|}{ main diagnostic/case } \\
\hline $\mathrm{ASD}(+\mathrm{PDA})$ & 7 & 3 & \\
\hline$A S D+P S(+P D A)$ & 9 & 7 & \\
\hline $\operatorname{VSD}(+\mathrm{PDA})$ & 29 & 28 & \\
\hline$V S D+P S$ & 5 & 0 & \\
\hline$V S D+A S D(+P D A)$ & 27 & 29 & \\
\hline PS & 0 & 5 & \\
\hline PAPVC+ASD & 1 & 4 & \\
\hline PECD & 0 & 1 & \\
\hline TOF & 1 & 2 & \\
\hline $\mathrm{EF} / \%$ & $69.46 \pm 6.19$ & $69.88 \pm 6.97$ & 0.689 \\
\hline WBCs $/\left(10^{*} 9 / \mathrm{L}\right)$ & $9.13 \pm 2.67$ & $8.64 \pm 2.48$ & 0.240 \\
\hline neutrophil percentage/\% & $29.49 \pm 12.28$ & $31.91 \pm 12.55$ & 0.230 \\
\hline $\mathrm{Hb} /(\mathrm{g} / \mathrm{dL})$ & $11.88 \pm 1.67$ & $12.18 \pm 1.81$ & 0.280 \\
\hline platelets/(10*9/L) & $338.62 \pm 89.67$ & $332.72 \pm 110.86$ & 0.718 \\
\hline $\mathrm{CRP} /(\mathrm{mg} / \mathrm{L})$ & $0.93 \pm 1.95$ & $0.62 \pm 0.95$ & 0.198 \\
\hline blood glucose/(mmol/L) & $4.68 \pm 0.81$ & $4.68 \pm 0.88$ & 0.950 \\
\hline total bilirubin/( $\mu \mathrm{mol} / \mathrm{L})$ & $7.17 \pm 5.27$ & $9.01 \pm 9.27$ & 0.134 \\
\hline creatinine/( $\mu \mathrm{mol} / \mathrm{L})$ & $24.31 \pm 8.95$ & $24.41 \pm 6.08$ & 0.937 \\
\hline
\end{tabular}

ASD atrial septal defect, $P D A$ patent ductus arteriosus, $P S$ pulmonary stenosis, VSD ventricular septal defect, PAPVC partial anomalous pulmonary venous connection, $P E C D$ partial endocardial cushion defect, TOF tetralogy of Fallot, EF ejection fraction, WBC white blood cell, $H b$ hemoglobin, CRP C-reactive protein

the gas-blood mixed liquid is suctioned into the reservoir of the oxygenator, leading to a reduction of negative pressure in the venous tube and in the inlet of the reservoir [11]. As a result, the negative pressure in the reservoir changes. Therefore, we routinely monitored the negative pressure in the reservoir, and the monitored value was equivalent to the set value. A high level of negative pressure may cause hemolysis. Usually, the highest negative pressure is $-60 \mathrm{mmHg}$ [12]. For the patients under $10 \mathrm{~kg}$, the VAVD negative pressure of $(-20 \sim-60) \mathrm{mmHg}$ do

Table 3 Comparison of the intraoperative clinical data between the two groups

\begin{tabular}{llll}
\hline Intraoperative data & Low-priming volume group (group A, $n=79)$ & Traditional group (group B, $n=79)$ & $p$ value \\
\hline CPB time/min & $72.41 \pm 23.10$ & $73.22 \pm 28.25$ & 0.844 \\
aortic cross-clamping time/min & $34.54 \pm 22.09$ & $35.01 \pm 21.89$ & 0.894 \\
priming volume of CPB/ml & $170.63 \pm 14.70$ & $274.55 \pm 48.96$ & $0.000^{* *}$ \\
PRBCs used in the priming of CPB/ml & $34.23 \pm 23.93$ & $108.04 \pm 57.17$ & $0.000^{* *}$ \\
CPB with booldless priming/case(\%) & $26(32.9 \%)$ & $12(15.2 \%)$ & $0.009^{* *}$ \\
CPB with no transfusion/case(\%) & $11(13.9 \%)$ & $7(8.9 \%)$ & 0.483 \\
total amount of PRBCs transfused during CPB/ml & $189.11 \pm 101.47$ & $244.30 \pm 96.41$ & $0.001^{* *}$ \\
PRBCs transfused by the anaesthetists/ml & $11.54 \pm 37.73$ & $1.90 \pm 16.87$ & $0.042^{*}$ \\
PRBCs transfused during the whole operation/ml & $200.51 \pm 101.74$ & $246.20 \pm 96.00$ & $0.004^{* *}$ \\
Hb during CPB/(g/dL) & $8.95 \pm 1.15$ & $9.93 \pm 1.92$ & $12.25 \pm 1.78$ \\
Hb before CPB weaning/(g/dL) & $11.51 \pm 1.33$ & $0.000^{* *}$ \\
\hline CPB cardi & $0.003^{* *}$ \\
\hline
\end{tabular}

$C P B$ cardiopulmonary bypass, $P R B C s$ packed red blood cells, $\mathrm{Hb}$ hemoglobin

${ }^{*}$ was $p<0.05,{ }^{* *}$ was $p<0.01$ 
Table 4 Comparison of the postoperative clinical data between the two groups

\begin{tabular}{|c|c|c|c|}
\hline Postoperative data & Low-priming-volume group (group A, $n=79$ ) & Traditional group (group $B, n=79$ ) & $p$ value \\
\hline $\mathrm{Hb}$ on the first day after surgery/(g/dL) & $13.12 \pm 1.75$ & $12.07 \pm 1.67$ & $0.000^{* *}$ \\
\hline Hb before hospital discharge/(g/dL) & $11.53 \pm 1.45$ & $11.22 \pm 1.61$ & 0.199 \\
\hline lowest value of platelet count/(10*9/L) & $208.85 \pm 70.07$ & $186.38 \pm 58.26$ & $0.030^{*}$ \\
\hline highest value of $\mathrm{WBCs} /\left(10^{*} 9 / \mathrm{L}\right)$ & $13.55 \pm 3.82$ & $12.72 \pm 4.34$ & 0.206 \\
\hline highest value of neutrophil percentage/\% & $76.42 \pm 8.48$ & $76.57 \pm 10.51$ & 0.923 \\
\hline highest value of CRP/(mg/L) & $49.86 \pm 41.09$ & $40.12 \pm 32.47$ & 0.143 \\
\hline highest value of lactic acid/(mmol/L) & $2.30 \pm 1.48$ & $2.32 \pm 1.40$ & 0.916 \\
\hline highest value of blood glucose/(mmol/L) & $12.40 \pm 6.07$ & $12.07 \pm 5.09$ & 0.722 \\
\hline highest value of temperature $/{ }^{\circ} \mathrm{C}$ & $38.20 \pm 2.28$ & $38.51 \pm 0.51$ & 0.239 \\
\hline highest value of total bilirubin/( $\mu \mathrm{mol} / \mathrm{L})$ & $18.00 \pm 14.28$ & $19.14 \pm 14.37$ & 0.630 \\
\hline highest value of creatinine/( $\mu \mathrm{mol} / \mathrm{L})$ & $32.67 \pm 9.64$ & $34.58 \pm 14.96$ & 0.361 \\
\hline \multicolumn{4}{|l|}{ incidence of pneumonia } \\
\hline unilateral pneumonia/case (rate) & $24(30.4 \%)$ & $21(26.6 \%)$ & 0.597 \\
\hline bilateral pneumonia/case (rate) & $28(35.4 \%)$ & $26(32.9 \%)$ & 0.737 \\
\hline thoracic drainage fluid $48 \mathrm{~h}$ after surgery $/ \mathrm{ml}$ & $98.23 \pm 54.83$ & $93.54 \pm 48.44$ & 0.570 \\
\hline urine volume $48 \mathrm{~h}$ after surgery $/ \mathrm{ml}$ & $825.50 \pm 265.90$ & $774.73 \pm 297.42$ & 0.384 \\
\hline mechanical ventilation time/h & $26.26 \pm 35.28$ & $25.16 \pm 37.81$ & 0.850 \\
\hline length of ICU stay/d & $2.50 \pm 2.48$ & $2.55 \pm 2.29$ & 0.910 \\
\hline length of postoperative stay in the general ward/d & $8.26 \pm 4.56$ & $8.22 \pm 3.17$ & 0.939 \\
\hline
\end{tabular}

*was $p<0.05,{ }^{* *}$ was $p<0.01$

$H b$ hemoglobin, WBC white blood cell, CRP C-reactive protein, PRBCs packed red blood cells

not change the degree of hemolysis [12]. Another complication associated with the VAVD controller is that the bubble from the oxygenator precipitate into the blood, leading to gas embolism. However, in our study, no visible hemoglobinuria or obvious increases in bilirubin were observed in either group, and no obvious organ disfunctions were observed postoperatively. Therefore, the VAVD remains an important auxiliary means for reducing the priming volume of $\mathrm{CPB}$ in pediatric cardiac surgery. Secondly, in addition to venous drainage, arterial perfusion should also be noted. In our study, the inner diameter of the artery tube was $3 / 16 \mathrm{in}$. in children with a body weight less than $10 \mathrm{~kg}$. But a study shows that the priming volume of CPB might be reduced slightly while the arterial pressure is increased, leading to the possibility of hemolysis [13]. Besides, the increased circulation resistance might result in a loss of hemodynamic energy delivered to patients, leading to a drop in the blood pressure of patients [13]. But in our study, patients had normal blood pressure and mixed $\mathrm{SvO} 2$ and had no significant increase in lactate levels, indicating that tissue perfusion is sufficient. Thirdly, in the low-priming-volume group, the oxygenator was located close to the operation bed and the patient's head, which limited the operating space of the assistant but did not affect the surgeon. Not all cardiac surgeons were willing to accept this limitation. Fourthly, when the $\mathrm{CPB}$ tubes was located close to the operation bed, the aseptic principle was easily violated. However, our study results showed the patients in the low-primingvolume group demonstrated no increase in the maximum postoperative temperature, and there was no positive blood culture in either group. Therefore, as long as the principles of the aseptic manipulation are strictly observed, $\mathrm{CPB}$ with low-priming volume does not increase the incidence of postoperative infection.

The contact between blood and biomaterial surface of CPB circuit results in platelet adhesion, WBC and coagulation system activation. An activated systemic inflammatory response syndrome leads to systemic organ dysfunction in pediatric patients and prolongs the length of ICU stay for 3 days [14]. Animal studies shows that decrease CPB surface area and the priming volume can decrease the levels of the inflammatory markers during $\mathrm{CPB}$ at $60 \mathrm{~min}$, but there is no difference during $\mathrm{CPB}$ at $120 \mathrm{~min}$. Therefore, the release of inflammatory markers during $\mathrm{CPB}$ is associated not only with the size of the contact area between the blood and biomaterial surface but also with the CPB time [2]. In our study, the inflammatory markers of the highest values of WBC number, the neutrophil percentage and CRP showed no significant difference between the two groups. The reason might be that although there was a significant difference in priming volume between the two groups, such a difference could not cause a significant difference in 
inflammatory response. The minimum priming volume found in an advanced heart center was only $73 \mathrm{ml}$ [7], so there is still much room for improvement in our equipment to reduce the priming volume. In addition, a Terumo membrane oxygenator with a hydrophilic coating was adopted for all patients in our study, which could have improved the blood compatibility of biomaterials and reduced the activation of the inflammatory response [15]. Besides, in our study, albumin was primed in the reservoirs and was coated on the inner surface of reservoirs and tubes before $\mathrm{CPB}$ in order to reduce the adhesion of platelets and the activation of non-physiological reactions. All these factors might have reduced the difference in the value of inflammatory markers between the two groups.

Reducing the lengths and the inner diameters of the $\mathrm{CPB}$ tubes decreases the priming volume and blood transfusions $[3,8]$, and reduces the rate of utilization of extracorporeal membrane oxygenation (ECMO) in newborns postoperatively [8], and does not increase postoperative complications or mortality [16]. In the lowpriming-volume group of our study, although the preoperative $\mathrm{Hb}$ concentration was lower, the amount of PRBCs usaged during CPB was lower and the postoperative $\mathrm{Hb}$ concentration was higher. This means that reducing the priming volume of $\mathrm{CPB}$ is the key to alleviating hemodilution, reducing PRBCs transfusions and maintaining a similar $\mathrm{Hb}$ concentration before hospital discharge in children. Studies shows that pediatric transfusions are associated with a prolonged postoperative mechanical ventilation time and lengths of ICU stay, a higher lactic acid level and an increased bleeding volume $48 \mathrm{~h}$ after surgery $[3,5,17]$, and even become an independent risk factor for postoperative mortality [4]. Transfusions after CPB are less complicated than transfusions during $\mathrm{CPB}$ [17]. The reason is that transfusions during $\mathrm{CPB}$ make PRBCs easily form into microaggregates and the brittleness of RBCs membrane increases, which lead to microcirculation embolism easier; Blood transfusions cause an increase in the erythrocyte morphological index and a decrease in the deformation index during CPB [18]; The high shear force during CPB can easily damage RBCs and lead to hemolysis, and these conditions are also associated with transfusion-related lung injury [19]. Therefore, Boettcher Wolfgang believes that routine application of bloodless priming in neonatal open-heart surgery is safe and that delaying transfusion until the end of $\mathrm{CPB}$ is beneficial for overall restrictive transfusions [5]. And so did our study, some patients with a body weight of more than $8 \mathrm{~kg}$ and a preoperative $\mathrm{Hb}$ concentration of more than $11 \mathrm{~g} / \mathrm{dL}$ were treated with bloodless priming. The amount of PRBCs used in the priming of $\mathrm{CPB}$ partially depended on the experience of perfusionists, and most importantly depended on the expected degree of hemodilution according to the priming volume of $\mathrm{CPB}$, body weights and $\mathrm{Hb}$ concentrations preoperatively. The rate of bloodless priming was statistically significant lower in group B than in group A, dealing with significantly higher PRBC transfusion rates. The body weights and $\mathrm{Hb}$ concentrations were similar in the two groups, so the larger priming volume of $\mathrm{CPB}$ may be an important factor for more RBC tranfusion rates. During $\mathrm{CPB}$, not all PRBCs were transfused while the $\mathrm{Hb}$ concentration reached the standard for $\mathrm{CPB}$ weaning. The remaining PRBCs were transfused from a peripheral vein by the anesthesiologists. This methods lead to a significant lower PRBCs transfusions and a higher $\mathrm{Hb}$ concentration postoperatively. And this result might be related to the decrease of transfusion-related complications and $\mathrm{RBC}$ destruction, suggesting that $\mathrm{CPB}$ with low-priming volume can reduce the usage of PRBCs and improve the use efficiency of PRBCs. There were no difference of the postoperative results between the two groups, possibly as these patients were not in critical illness and may not be susceptible to transfusions. There is another result need to be pay attention to. That is, the rate of bloodless priming of CPB was significant higher in the low-priming-volume group, but the number of patients without transfusions during the whole operation was still very rare. In our study, patients escaping from transfusions were those who had a heavier body weight and higher $\mathrm{Hb}$ concentrations preoperatively. Although at present, the effects of hemodilution on children are not fully understood, and the minimum safe hematocrit and the general accepted transfusion threshold during $\mathrm{CPB}$ in children have not been standardized, for patients not in critical illness and have a heavier body weight, the usage of PRBCs maybe too much in our study. Maybe some patients could have escaped from transfusions, but we perfusionist prepared too much PRBCs in advance preoperatively. So we need to decrease the usage of PRBCs in the low risk and simple cases in the future. Blood conservation is a team project, so in order to make significant progress in maintaining a blood reserve, perfusionists, surgeons, anesthesiologists, and especially perfusionists, need to be more proactive in reducing usage of blood products.

In this study, the lowest postoperative platelet count was significantly higher in the low-priming volume group than in the traditional group. The decrease in the platelet count of children after CHD surgery with $\mathrm{CPB}$ was related to hemodilution, the contact between the blood and biomaterial surface leading to platelet activation and consumption, the $\mathrm{CPB}$ time, the aortic crossclamping time and the intraoperative temperature, etc [20]. Platelet dysfunction after cardiac surgery is an important factor for bleeding after surgery [21]. In our study, there was no significant difference in CPB time, 
aortic cross-clamping time or temperature during the aortic cross-clamping process between the two groups. Therefore, $\mathrm{CPB}$ with low-priming volume might be a protective factor for maintaining platelet count. However, in this study, there was no significant difference in postoperative thoracic drainage fluid $48 \mathrm{~h}$ after surgery between the two groups. The reason might be that although the platelet count was decreased, it was still in the normal range, thus reducing the influence on coagulation function, and a few patients with postoperative transfusions of plasma might have affected the analysis of the results.

This study had three limitations. Firstly, this is a retrospective study, so it may have sample selection bias. Secondly, patients with complicated CHD surgery or in a critical condition were excluded in our study, but the value of miniaturization of the $\mathrm{CPB}$ circuit maybe more meaningful in the more complex and smaller children, so this study is limited by the excluded patients, which requires us to study further. Thirdly, in our study, the number of patients without transfusions during the whole operation was still very rare. This is an unfortunate result which prevents us from further study due to the rare case of transfusion-free patients. So we need to decrease the usage of PRBCs in the low risk and simple cases in the future.

\section{Conclusions}

The usage of the PRBCs during $\mathrm{CPB}$ with low-priming volume decreased significantly, but the postoperative $\mathrm{Hb}$ concentration and platelet count could still be maintained at a high level, improving the use efficiency of the PRBCs. CPB with low-priming volume did not increase the risk of hemolysis or the incidence of postoperative infection and did not affect the postoperative recovery of patients, so it is worthy of continuous promotion and optimization.

\section{Abbreviations \\ CPB: Cardiopulmonary bypass; CHD: Congenital heart disease; PRBCs: Packed red blood cells; Hb: Hemoglobin; EF: Ejection fraction; RACHS-1: Risk adjustment in congenital heart surgery; WBC: White blood cell; CRP: C- Reactive protein; ASD: Atrial septal defect; PDA: Patent ductus arteriosus; PS: Pulmonary stenosis; VSD: Ventricular septal defect; PAPVC: Partial anomalous pulmonary venous connection; PECD: Partial endocardial cushion defect; TOF: Tetralogy of Fallot; VAVD: Vacuum-assist venous drainage; SvO2: Venous oxygen saturation; ECMO: Extracorporeal membrane oxygenation}

\section{Acknowledgements}

Not applicable.

\section{Authors' contributions}

LW collected the data, conceived and wrote the manuscript. QC, YQQ, JXY, JZD, XCL, YTH, LWC reviewed the manuscript. The author(s) read and approved the final manuscript.

\section{Funding}

This study is not funded.

\section{Availability of data and materials}

The datasets during and/or analysed during the current study available from the corresponding author on reasonable request.

Ethics approval and consent to participate

Not applicable.

\section{Consent for publication}

Not applicable.

\section{Competing interests}

The authors declare that they have no competing interests.

Received: 29 February 2020 Accepted: 10 May 2020

Published online: 27 May 2020

\section{References}

1. Donmez A, Yurdakok O. Cardiopulmonary bypass in infants. J Cardiothorac Vasc Anesth. 2014;28:778-88.

2. Fujii Y, Shirai M, Takewa Y, Tatsumi E. Cardiopulmonary bypass with lowversus high-priming volume. ASAIO J. 2016;62:286-90.

3. Boettcher W, Redlin M, Dehmel F, Graefe K, Cho MY, Habazettl H, et al. Asanguineous priming of miniaturized paediatric cardiopulmonary bypass circuits for congenital heart surgery: independent predictors associated with transfusion requirements and effects on postoperative morbidity. Eur J Cardiothorac Surg. 2018:53:1075-81.

4. Murin P, Boettcher W, Ozaki S, Wloch A, Cho MY, Redlin M, et al. Asanguineous cardiopulmonary bypass in infants: impact on postoperative mortality and morbidity. Thorac Cardiovasc Surg. 2019. https://doi.org/10. 1055/s-0038-1676789.

5. Boettcher W, Sinzobahamvya N, Miera O, Redlin M, Dehmel F, Cho MY, et al. Routine application of bloodless priming in neonatal cardiopulmonary bypass: a 3-year experience. Pediatr Cardiol. 2017;38:807-12.

6. Willems A, Datoussaid D, Tucci M, Torres CS, Villé AD, Fils JF, et al. Impact of on-bypass red blood cell transfusion on severe postoperative morbidity or mortality in children. Anesth Analg. 2016;123:420-9.

7. Wloch A, Boettcher W, Sinzobahamvya N, Cho MY, Redlin M, Dähnert I, et al. Bloodless priming of the cardiopulmonary bypass circuit: determinants of successful transfusion-free operation in neonates and infants with a maximum body weight of $7 \mathrm{~kg}$. Cardiol Young. 2018;28:1141-7.

8. Kim SY, Cho S, Choi E, Kim WH. Effects of mini-volume priming during cardiopulmonary bypass on clinical outcomes in low-bodyweight neonates: less transfusion and postoperative extracorporeal membrane oxygenation support. Artif Organs. 2016:4:73-9.

9. Harvey B, Shann KG, Fitzgerald D, Mejak B, Likosky DS, Puis L, et al. International pediatric perfusion practice: 2011 survey results. J Extra Corpor Technol. 2012;44:186-93.

10. Vida VL, Bhattarai A, Speggiorin S, Zanella F, Stellin G. Effect of vacuum on venous drainage: an experimental evaluation on pediatric venous cannulas and tubing systems. J Nepal Med Assoc. 2014;52:960-6.

11. Shade BC, Melchior RW, Fisher DR, High R, Mascio CE, Rosenthal TM, et al. Comparison of three infant venous reservoirs with vacuum-assisted venous drainage during varying levels of cardiotomy suction. Perfusion. 2019. https://doi.org/10.1177/0267659119850344.

12. Kwak JG, Lee J, Park M, Seo YJ, Lee CH. Hemolysis during open-heart surgery with vacuum-assisted venous drainage at different negative pressures in pediatric patients weighing less than 10 kilograms. World J Pediatr Congenit Heart Surg. 2017:8:161-5.

13. Wang $S$, Rosenthal $T$, Kunselman $A R$, Ündar A. Evaluation of different diameter arterial tubing and arterial cannulae in simulated neonatal/ pediatric cardiopulmonary bypass circuits. Artif Organs. 2015;39:43-52

14. Boehne M, Sasse M, Karch A, Dziuba F, Horke A, Kaussen T, et al. Systemic inflammatory response syndrome after pediatric congenital heart surgery: incidence, risk factors, and clinical outcome. J Card Surg. 2017;32:116-25.

15. Hirata Y. Cardiopulmonary bypass for pediatric cardiac surgery. Gen Thorac Cardiovasc Surg. 2018;66:65-70.

16. Kwak JG, Park MK, Lee JK, Lee CH. Multiple approaches to minimize transfusions for pediatric patients in open-heart surgery. Pediatr Cardiol. 2016;37:44-9.

17. Redlin M, Boettcher W, Kukucka M, Kuppe H, Habazettl H. Blood transfusion during versus after cardiopulmonary bypass is associated with postoperative morbidity in neonates undergoing cardiac surgery. Perfusion. 2014;29:327-32. 
18. Ichikawa J, Koshino I, Arashiki N, Nakamura F, Komori M. Changes in erythrocyte morphology at initiation of cardiopulmonary bypass without blood transfusion were not associated with less deformability during cardiac surgery. J Cardiothorac Vasc Anesth. 2019:33:2960-7.

19. Mulder HD, Augustijn QJ, van Woensel JB, Bos AP, Juffermans NP, Wöstenvan Asperen RM, et al. Incidence, risk factors, and outcome of transfusionrelated acute lung injury in critically ill children: a retrospective study. J Crit Care. 2015;30:55-9.

20. Bonding Andreasen J, Hvas AM, Ravn HB. Marked changes in platelet count and function following pediatric congenital heart surgery. Paediatr Anaesth. 2014;24:386-92.

21. Ranucci M, Pistuddi V, Di Dedda U, Menicanti L, De Vincentiis C,

Baryshnikova E. Platelet function after cardiac surgery and its association with severe postoperative bleeding: the PLATFORM study. Platelets. 2018;30: 908-14.

\section{Publisher's Note}

Springer Nature remains neutral with regard to jurisdictional claims in published maps and institutional affiliations.

Ready to submit your research? Choose BMC and benefit from:

- fast, convenient online submission

- thorough peer review by experienced researchers in your field

- rapid publication on acceptance

- support for research data, including large and complex data types

- gold Open Access which fosters wider collaboration and increased citations

- maximum visibility for your research: over $100 \mathrm{M}$ website views per year

At BMC, research is always in progress.

Learn more biomedcentral.com/submissions 